\title{
Interaction of Two Water Soluble Heterocyclic Hydrazones on Copper in Nitric Acid: Electrochemical, Surface Morphological, and Quantum Chemical Investigations
}

\author{
Vinod P. Raphael, ${ }^{1}$ Joby Thomas Kakkassery, ${ }^{2}$ Shaju K. Shanmughan, ${ }^{1}$ and Sini Varghese ${ }^{2}$ \\ ${ }^{1}$ Department of Chemistry, Government Engineering College Thrissur, Kerala 680009, India \\ ${ }^{2}$ Department of Chemistry, St. Thomas' College (Autonomous) Thrissur, Kerala 680001, India \\ Correspondence should be addressed to Vinod P. Raphael; vinodpraphael@gmail.com
}

Received 23 June 2016; Revised 22 September 2016; Accepted 13 October 2016

Academic Editor: Manoj Gupta

Copyright (C) 2016 Vinod P. Raphael et al. This is an open access article distributed under the Creative Commons Attribution License, which permits unrestricted use, distribution, and reproduction in any medium, provided the original work is properly cited.

\begin{abstract}
Two novel heterocyclic compounds (E)-2-(1-(pyridin-3-yl)ethylidene)hydrazinecarbothioamide (3APTSC) and (E)-3-(1-(2phenylhydrazono)ethyl)pyridine (3APPH) derived from 1-(pyridin-3-yl)ethanone were synthesized and characterized by various spectroscopic techniques. The corrosion inhibition efficacies of these compounds on copper in $0.1 \mathrm{M} \mathrm{HNO}_{3}$ were screened by electrochemical corrosion monitoring techniques such as potentiodynamic polarization studies and impedance spectroscopy. Investigations clearly established that $3 \mathrm{APPH}$ displayed higher corrosion inhibition efficiency on $\mathrm{Cu}$ than 3APTSC at all concentrations. The mechanism of inhibition was verified with the help of adsorption isotherms. 3APTSC and 3APPH obeyed Langmuir adsorption isotherm on $\mathrm{Cu}$ surface. Thermodynamic parameters such as adsorption equilibrium constant $\left(K_{\text {ads }}\right)$ and free energy of adsorption $\left(\Delta G_{\text {ads }}\right)$ were also evaluated. Potentiodynamic polarization investigations confirmed that the 3APTSC and $3 \mathrm{APPH}$ act as mixed type inhibitors. Surface analysis of the metal specimens was performed by scanning electron microscopy. Energy of HOMO and LUMO, their difference, number of electrons transferred, electronegativity, chemical hardness, and so forth were evaluated by quantum chemical studies. Agreeable correlation was observed between the results of quantum chemical calculations and other corrosion monitoring techniques.
\end{abstract}

\section{Introduction}

The only engineering metal that is relatively behaving as a noble metal is copper, which requires strong oxidizing agents for its corrosion or dissolution. But during certain industrial processes copper tarnishes or corrodes. Copper has an inevitable role in electronic industry. The chemical dissolution and electroplating of copper are the main processes used in the fabrication of electronic devices. The most widely used aggressive solution contains nitric acid and hence this medium has induced a great deal of research on copper corrosion [1-4]. The most practical way to decrease the rate of corrosion in acidic medium is the use of corrosion inhibitors. Recently, researchers have shown that certain organic compounds create a barrier against the tarnishing of copper. Most of the excellent acid inhibitors are organic compounds containing nitrogen, oxygen, phosphorus, and sulphur. Organic compounds containing electron rich functional groups, $\pi$ electrons in triple or conjugated double bonds, and heteroatoms such as nitrogen, sulfur, and oxygen are usually acting as good inhibitors since these compounds are easily adsorbed on metal surfaces [5-13]. Structure and geometry of a molecule have a definite role in preventing the corrosion of metal in acid medium. Studies on the relation between adsorption and corrosion inhibition are of considerable importance. In the present paper, the inhibition of copper corrosion by two water soluble heterocyclic hydrazones in $0.1 \mathrm{M} \mathrm{HNO}_{3}$ has been investigated electrochemically and quantum chemically. 

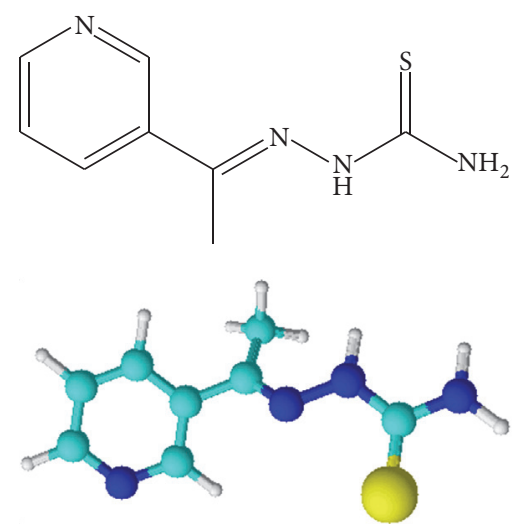

FIGURE 1: Structure and optimized geometry of 3APTSC.

\section{Materials and Methods}

2.1. Synthesis. All chemicals and reagents were purchased from Merck. Heterocyclic hydrazones were prepared by the condensation between equimolar amounts of 3-acetylpyridine and amino compounds such as thiosemicarbazide and phenyl hydrazine in ethanol medium. The reaction mixture was refluxed for 2 hours, cooled in ice bath, filtered, dried, and characterized by various spectroscopic techniques.

3APTSC. Anal. calcd for $\mathrm{C}_{8} \mathrm{H}_{10} \mathrm{~N}_{4} \mathrm{~S}: \mathrm{C}, 49.49 ; \mathrm{H}, 5.15 ; \mathrm{N}$, 28.9, S 16.49\%. Found C, 48.55; H, 4.99; N, 29.22, S 16.82\%. Mass: $m / z: 194\left(\mathrm{M}^{+}\right) .{ }^{1} \mathrm{Hnmr}: 2.34 \delta\left(\mathrm{CH}_{3}\right), 3.37 \delta\left(\mathrm{NH}_{2}\right)$, $8.09 \delta(\mathrm{NH}) .{ }^{13} \mathrm{Cnmr}: 13,72 \mathrm{ppm}\left(\mathrm{CH}_{3}\right), 145.55 \mathrm{ppm}(\mathrm{C}=\mathrm{N})$. IR: $1612 \mathrm{~cm}^{-1}\left(v_{\mathrm{C}=\mathrm{N}}\right), 3201 \mathrm{~cm}^{-1}\left(v_{\mathrm{N}-\mathrm{H}}\right), 880 \mathrm{~cm}^{-1}(\mathrm{C}=\mathrm{S})$. UVvis: $31948 \mathrm{~cm}^{-1}\left(\pi \rightarrow \pi^{*}\right), 31347 \mathrm{~cm}^{-1}\left(\mathrm{n} \rightarrow \pi^{*}\right)$.

3APPH. Anal. calcd for $\mathrm{C}_{13} \mathrm{H}_{13} \mathrm{~N}_{3}$ : C, 73.93; $\mathrm{H}, 6.16 ; \mathrm{N}, 19.9 \%$. Found C, 73.47; H, 6.42; N, 19.44\%. Mass: $m / z: 211\left(\mathrm{M}^{+}\right)$. ${ }^{1} \mathrm{Hnmr}: 2.28 \delta\left(\mathrm{CH}_{3}\right), 9.86 \delta(\mathrm{NH}) .{ }^{13} \mathrm{Cnmr}: 12.53 \mathrm{ppm}\left(\mathrm{CH}_{3}\right)$, 137.99 ppm $(\mathrm{C}=\mathrm{N})$. IR: $1593 \mathrm{~cm}^{-1}\left(v_{\mathrm{C}=\mathrm{N}}\right), 3265 \mathrm{~cm}^{-1}\left(v_{\mathrm{N}-\mathrm{H}}\right)$. UV-vis: $32679 \mathrm{~cm}^{-1}\left(\pi \rightarrow \pi^{*}\right), 29239 \mathrm{~cm}^{-1}\left(\mathrm{n} \rightarrow \pi^{*}\right)$.

Figures 1 and 2 show the molecular and optimized structures of the organic compounds 3APTSC and 3APPH, respectively.

2.2. Electrochemical Measurements. Copper strips containing 99.4 wt.\% Cu, 0.0032 wt.\% Ni, 0.0095 wt.\% Al, 0.0081 wt.\% $\mathrm{Mn}$, and 0.125 wt.\% Si (determined by EDAX method) and balance traces of impurities and other elements were used for electrochemical studies. The copper samples were mechanically abraded using different grades of silicon carbide paper, washed with distilled water, and dried. Inhibitor solutions were prepared in the range $0.2-1.0 \mathrm{mM}$ concentration in $0.1 \mathrm{M} \mathrm{HNO}_{3}$ medium.

The electrolysis cell was a cubical glass vessel containing two openings. Two electrodes, namely, saturated calomel (reference) and platinum electrode, having $1 \mathrm{~cm}^{2}$ surface area were inserted from the top. The working electrode was copper strip in which the $1 \mathrm{~cm}^{2}$ area of the strip was exposed to the solution through the second opening. The copper specimen was exposed to the corroding medium for $1 \mathrm{~h}$ before
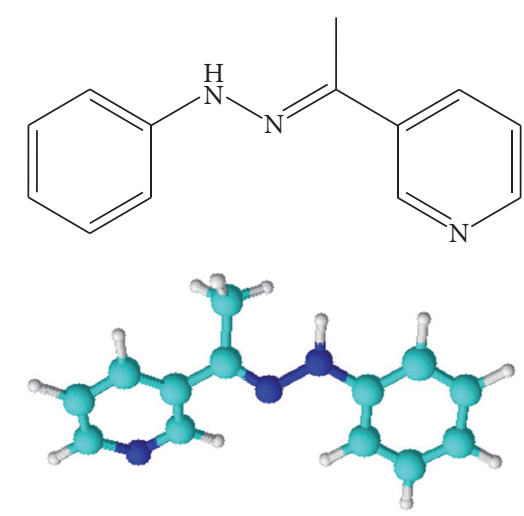

FIGURE 2: Structure and optimized geometry of 3APPH.

experiment to attain corrosion potential. All potentials were measured with reference to SCE. To avoid the effects of polarization, the reference electrode and the working electrode were kept very closely. Before each experiment, the electrode was polished using $\mathrm{SiC}$ paper of various grades. After this, the electrode was cleaned and degreased. Ivium Compactstate electrochemical system together with Iviumsoft software package was used to perform the experiments.

2.2.1. AC Impedance Studies. A frequency range of $1 \mathrm{KHz}$ to $100 \mathrm{mHz}$ with an amplitude of $10 \mathrm{mV}$ as excitation signal was employed for every experiment in impedance spectroscopy. The percentage of inhibition efficiency of molecules from impedance measurements was calculated using charge transfer resistance by the following expression $[14,15]$ :

$$
\eta_{\mathrm{EIS}} \%=\frac{R_{\mathrm{ct}}-R_{\mathrm{ct}}^{\prime}}{R_{\mathrm{ct}}} \times 100,
$$

where $R_{\mathrm{ct}}$ and $R_{\mathrm{ct}}^{\prime}$ are the charge transfer resistances of working electrode with and without inhibitor, respectively.

2.2.2. Potentiodynamic Polarization Measurements. Polarization plots were obtained in the electrode potential range from -100 to $+100 \mathrm{mV}$ Vs corrosion potential $\left(E_{\text {corr }}\right)$ at a sweep rate of $1 \mathrm{mV} / \mathrm{sec}$. To obtain corrosion current densities, Tafel polarization analyses were done by extrapolating anodic and cathodic curves. The percentage of inhibition efficiency $\left(\eta_{\text {pol }} \%\right)$ was evaluated from the measured $I_{\text {corr }}$ values using the following relation $[16,17]$ :

$$
\eta_{\text {pol }} \%=\frac{I_{\text {corr }}-I_{\text {corr }}^{\prime}}{I_{\text {corr }}} \times 100 \text {, }
$$

where $I_{\text {corr }}$ and $I_{\text {corr }}^{\prime}$ are the corrosion current densities of the exposed area of the working electrode in the absence and presence of inhibitor.

\section{Results and Discussion}

3.1. AC Impedance Study. The corrosion behaviour of copper, in acidic solution in the presence and absence of 3APTSC 


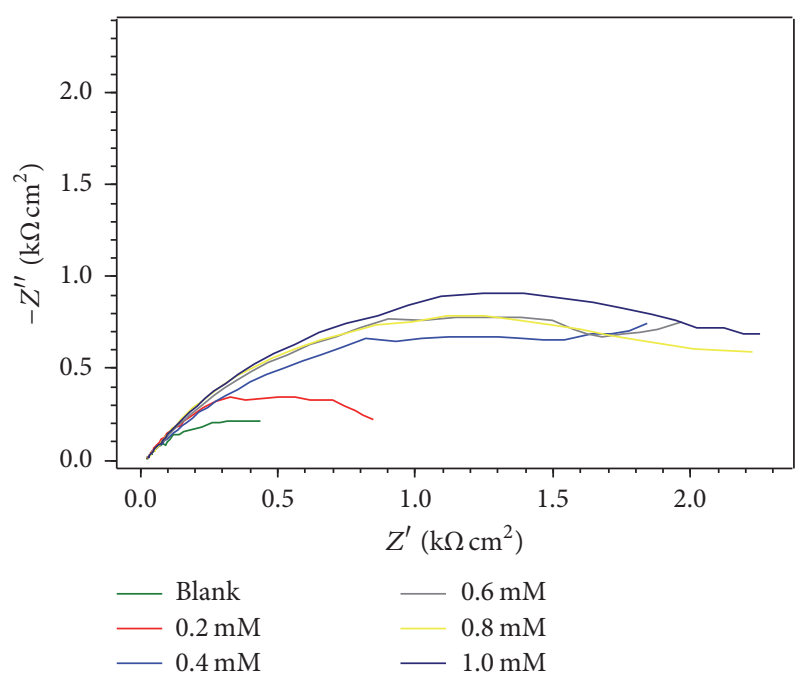

(a)

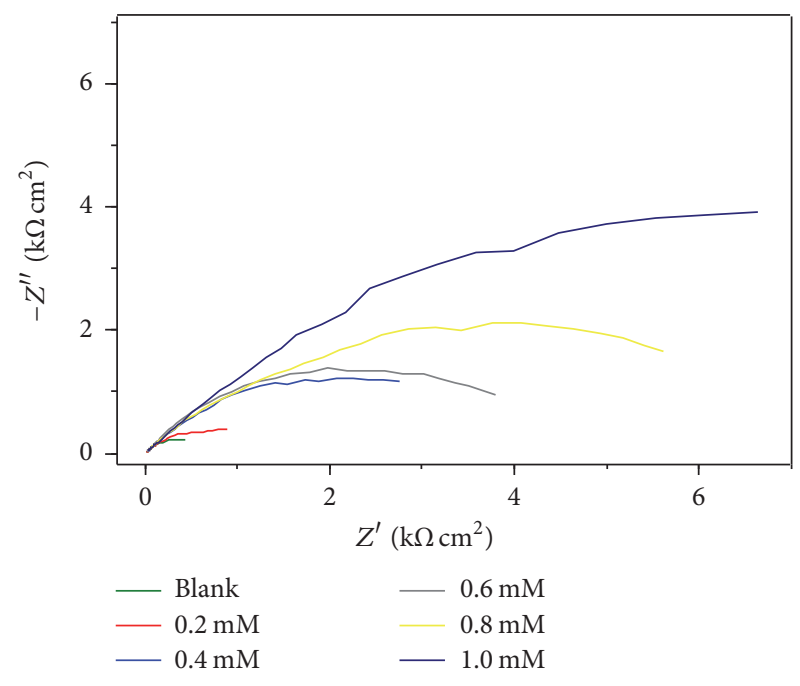

(b)

FIGURE 3: Nyquist plots for $\mathrm{Cu}$ in the absence and presence of (a) 3APTSC and (b) $3 \mathrm{APPH}$ in $0.1 \mathrm{M} \mathrm{HNO}_{3}$.

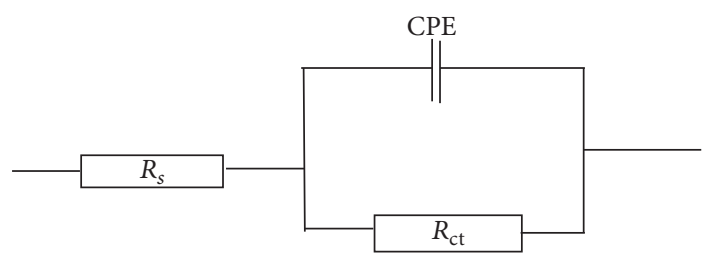

FIGURE 4: Equivalent circuit used to model impedance data in $0.1 \mathrm{M}$ $\mathrm{HNO}_{3}$ solution.

and $3 \mathrm{APPH}$ compounds, has been investigated by the electrochemical impedance spectroscopy (EIS) at $30^{\circ} \mathrm{C}$. The charge transfer resistance $\left(R_{\mathrm{ct}}\right)$ values were calculated from the difference in impedance at lower and higher frequencies $[18,19]$.

Nyquist plots recorded for copper electrode in $0.1 \mathrm{M}$ $\mathrm{HNO}_{3}$ solution containing various concentrations of 3APTSC and 3APPH are shown in Figures 3(a) and 3(b), respectively. As can be seen from these figures, the Nyquist plots did not exhibit perfect semicircles expected by the EIS theory. The deviation from ideal semicircle can be attributed to the frequency dispersion [1] as well as the nonhomogeneous nature of the surface and mass transfer resistance $[20,21]$.

The analysis of Nyquist plots from experimental data is done by Randles equivalent circuit (Figure 4), in which $R_{s}$ represents the electrolyte resistance, $R_{\mathrm{ct}}$ represents the charge transfer resistance, and $\mathrm{CPE}$ indicates the constant phase element. Even in the absence of the inhibitor (blank) high value of impedance is observed. This may be due to the formation of oxide layer on the metal surface. Nyquist plots show that the impedance behaviour of copper has significantly altered by the addition of 3APTSC and $3 \mathrm{APPH}$ to the corroding medium. $R_{\mathrm{ct}}$ values are greater than that of uninhibited one and the impedance of inhibited systems increased with the concentration of organic molecules in nitric acid. The adsorption of inhibitor molecules on the metal surface decreased its electrical capacity because they displaced the water molecules and other ions originally adsorbed on the metal surface $[22,23]$. This layer builds a barrier for mass and charge transfer. The results illustrate that $R_{\mathrm{ct}}$ values increased with increase of inhibitor concentration. The electrochemical impedance parameters derived from the Nyquist plots and the inhibition efficiencies (\%) are shown in Table 1.

From Table 1 it is also evident that the inhibition efficiencies of $3 \mathrm{APPH}$ on copper surface are significantly greater than that of 3APTSC at all concentrations. Even at a lower concentration of $0.2 \mathrm{mM}$, the former one demonstrated very good inhibition response on the copper surface in nitric acid medium. The escalated inhibition power of $3 \mathrm{APPH}$ can be attributed to the presence of benzene ring in the molecule in addition to the heterocyclic ring and azomethine linkage. The interaction of aromatic rings and $\mathrm{C}=\mathrm{N}$ group with the copper atoms on the surface will be higher for $3 \mathrm{APPH}$ than for 3APTSC due to its structural characteristics.

3.2. Adsorption Isotherm. The most convenient way of expressing adsorption quantitatively is to derive the adsorption isotherm that characterizes the metal/inhibitor/environment system [24-26]. Attempts were made to fit $\theta$ values to various adsorption isotherms with the aid of correlation coefficient. Langmuir adsorption isotherm (3) fits well with the experimental data for $3 \mathrm{APTSC}$ and $3 \mathrm{APPH}$ on copper surface which are shown by Figures 5(a) and 5(b), respectively.

$$
\frac{C}{\theta}=\frac{1}{K_{\mathrm{ads}}}+C
$$

where $C$ is the concentration of the inhibitor, $\theta$ is the fractional surface coverage, and $K_{\mathrm{ads}}$ is the adsorption equilibrium constant [26].

It is well known that the standard adsorption free energy $\left(\Delta G_{\mathrm{ads}}^{\circ}\right)$ is related to equilibrium constant of adsorption $\left(K_{\mathrm{ads}}\right)$ by the following equation:

$$
\Delta G_{\mathrm{ads}}^{\circ}=-R T \ln \left(55.5 K_{\mathrm{ads}}\right),
$$




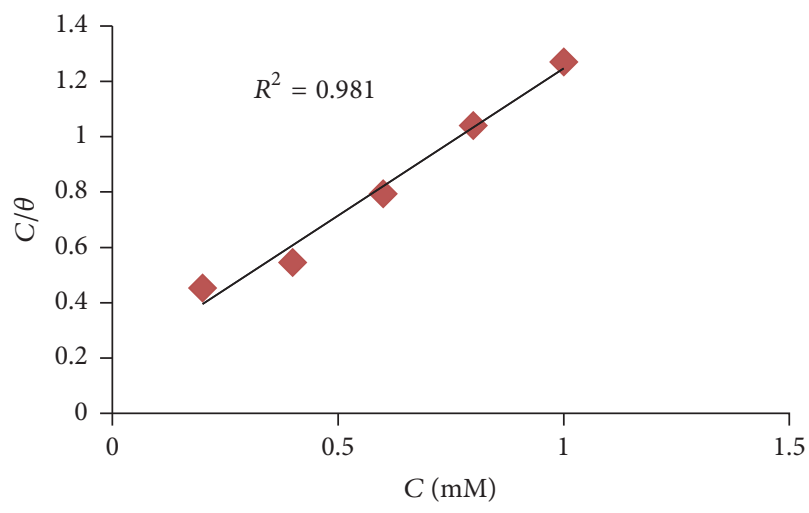

(a)

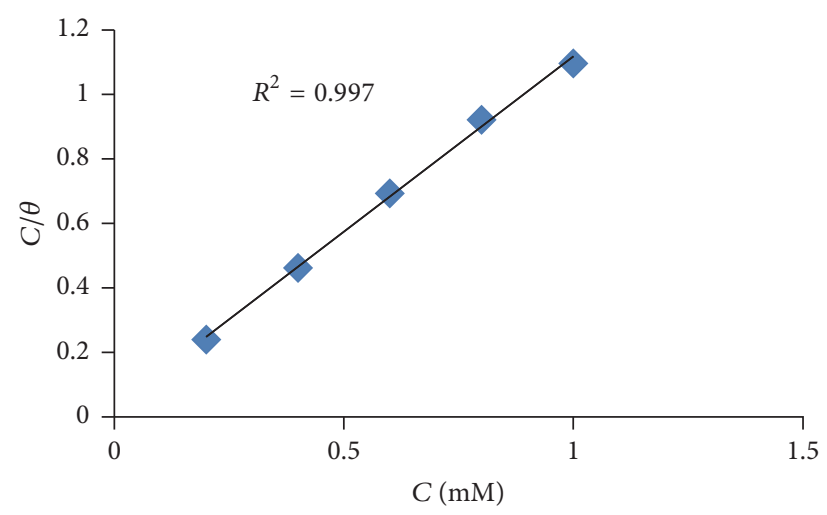

(b)

FIGURE 5: Langmuir adsorption isotherm for (a) 3APTSC and (b) $3 \mathrm{APPH}$ on $\mathrm{Cu}$ in $0.1 \mathrm{M} \mathrm{HNO}_{3}$.

TABLE 1: Impedance parameters of copper in the presence and absence of heterocyclic hydrazones in $0.1 \mathrm{M} \mathrm{HNO}_{3}$.

\begin{tabular}{|c|c|c|c|c|c|c|}
\hline & Blank & $0.2 \mathrm{mM}$ & $0.4 \mathrm{mM}$ & $0.6 \mathrm{mM}$ & $0.8 \mathrm{mM}$ & $1.0 \mathrm{mM}$ \\
\hline \multicolumn{7}{|l|}{ 3APTSC } \\
\hline$C_{\mathrm{dl}}{ }^{*}$ & 1166 & 415 & 132 & 110 & 113 & 101 \\
\hline$R_{\mathrm{ct}}{ }^{*}$ & 440 & 788 & 1643 & 1798 & 1906 & 2066 \\
\hline$\eta_{\mathrm{EIS}} \%$ & - & 44.16 & 73.22 & 75.53 & 76.91 & 78.70 \\
\hline \multicolumn{7}{|l|}{$3 \mathrm{APPH}$} \\
\hline$C_{\mathrm{dl}}$ & 1166 & 146 & 82 & 78 & 63 & 52 \\
\hline$R_{\mathrm{ct}}$ & 440 & 2661 & 3122 & 3245 & 3314 & 4961 \\
\hline$\eta_{\mathrm{EIS}} \%$ & - & 83.46 & 85.90 & 86.44 & 86.72 & 91.13 \\
\hline
\end{tabular}

TABLE 2: Adsorption parameters of heterocyclic hydrazones on $\mathrm{Cu}$ in $0.1 \mathrm{M} \mathrm{HNO}_{3}$.

\begin{tabular}{lc}
\hline 3 APTSC & \\
$K_{\text {ads }}$ & 5494 \\
$\Delta G_{\text {ads }}(\mathrm{kJ} / \mathrm{mol})$ & -31.8 \\
$3 \mathrm{APPH}$ & \\
$K_{\text {ads }}$ & 33333 \\
$\Delta G_{\mathrm{ads}}(\mathrm{kJ} / \mathrm{mol})$ & -36.4 \\
\hline
\end{tabular}

where 55.5 is the molar concentration of water, $R$ is the universal gas constant, and $T$ is the temperature in Kelvin [24]. The adsorption parameters are provided in Table 2.

Studies confirmed that the molecule $3 \mathrm{APPH}$ exhibited elevated adsorption equilibrium constant and free energy of adsorption on copper surface compared to 3APTSC. This is obviously due to the strong interaction of $3 \mathrm{APPH}$ molecules through the benzene ring in addition to the heterocyclic ring and azomethine linkage. The magnitudes of free energy of adsorptions indicate that these molecules interact on the metal surface through both physisorption and chemisorptions [23].

3.3. Potentiodynamic Studies. The Pourbaix diagram for copper-water system $[27,28]$ has revealed that the copper is corroded to $\mathrm{Cu}^{2+}$ in nitric acid solutions. Though the chance for the formation of oxide film is rare in acidic medium, it is forced to believe that appreciable oxide layer is present on the surface due to very low value of corrosion current density and high value of impedance in the absence of inhibitor. The electrochemical reactions for copper in nitric acid solution can be described as follows.

At anode the dissolution of copper is controlled by diffusion of soluble $\mathrm{Cu}$ (II) species from the outer layer to the bulk solution. Since static electrodes are used for electrochemical studies this step can be considered as the rate diffusion step.

$$
\mathrm{Cu} \longrightarrow \mathrm{Cu}^{2+}+2 \mathrm{e}
$$

At cathode, the interaction of copper in nitric acid involves reduction of the nitrate ion into nitrous acid or nitric oxide (see (7) and (8)). In aerated nitric acid solutions, dissolved oxygen may also be reduced on copper surface [29] (see (9)).

$$
\begin{gathered}
\mathrm{NO}^{3-}+3 \mathrm{H}^{+}+2 \mathrm{e} \longrightarrow \mathrm{HNO}_{2}+\mathrm{H}_{2} \mathrm{O} \\
\mathrm{NO}^{3-}+4 \mathrm{H}^{+}+3 \mathrm{e} \longrightarrow \mathrm{NO}+2 \mathrm{H}_{2} \mathrm{O} \\
\mathrm{O}_{2}+4 \mathrm{H}^{+}+4 \mathrm{e} \longrightarrow 2 \mathrm{H}_{2} \mathrm{O}
\end{gathered}
$$

The cathodic and anodic polarization curves for copper corrosion in the absence and presence of various concentrations of the inhibitors at room temperature were studied. It is obvious from the table that the current density of the blank 
TABLE 3: Electrokinetic parameters of copper in the presence and absence of heterocyclic hydrazones in $0.1 \mathrm{M} \mathrm{HNO}_{3}$.

\begin{tabular}{|c|c|c|c|c|c|c|}
\hline & Blank & $0.2 \mathrm{mM}$ & $0.4 \mathrm{mM}$ & $0.6 \mathrm{mM}$ & $0.8 \mathrm{mM}$ & $1.0 \mathrm{mM}$ \\
\hline \multicolumn{7}{|l|}{ 3APTSC } \\
\hline$E_{\text {corr }}{ }^{*}$ & 151 & 132 & 150 & 173 & 145 & 149 \\
\hline$I_{\text {corr }}$ & 9.5 & 5.63 & 3.6 & 3.33 & 2.30 & 2.28 \\
\hline$b_{a}$ & 71 & 70 & 126 & 119 & 87 & 95 \\
\hline$-b_{c}$ & 64 & 88 & 104 & 96 & 80 & 70 \\
\hline$\eta_{\mathrm{pol}} \%$ & - & 40.69 & 62.11 & 64.91 & 75.74 & 76.02 \\
\hline \multicolumn{7}{|l|}{$3 \mathrm{APPH}$} \\
\hline$E_{\text {corr }}$ & 151 & 142 & 98 & 117 & 99 & 117 \\
\hline$I_{\text {corr }}$ & 9.5 & 1.51 & 1.32 & 1.1 & 0.99 & 0.71 \\
\hline$b_{a}$ & 71 & 146 & 123 & 128 & 84 & 87 \\
\hline$-b_{c}$ & 64 & 109 & 121 & 107 & 98 & 105 \\
\hline$\eta_{\mathrm{pol}} \%$ & - & 84.10 & 86.10 & 88.42 & 89.57 & 92.52 \\
\hline
\end{tabular}

${ }^{*} E_{\text {corr }}$ in $\mathrm{mV} / \mathrm{SCE} ; I_{\text {corr }}$ in $\mu \mathrm{A} / \mathrm{cm}^{2} ; b_{c}$ in $\mathrm{mV} / \mathrm{dec} ; b_{a}$ in mv/dec.

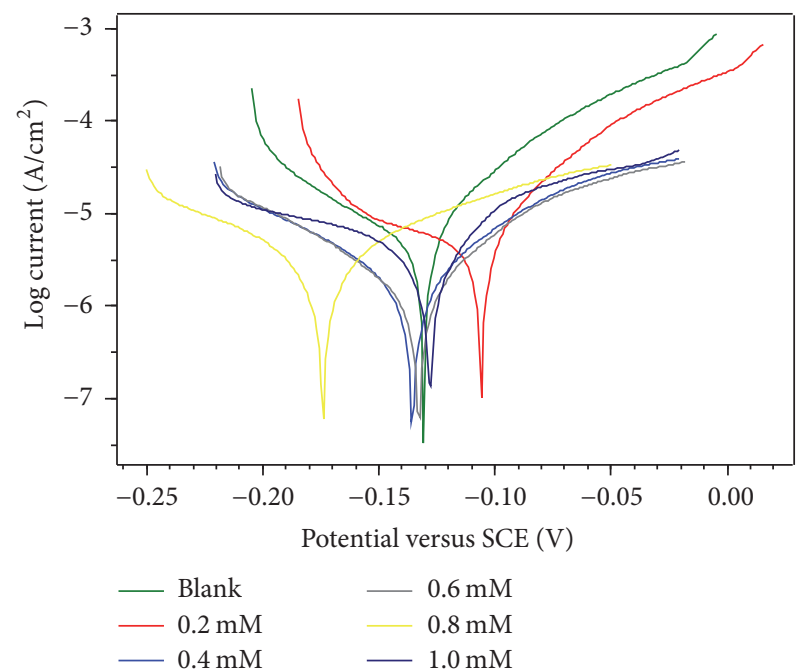

(a)

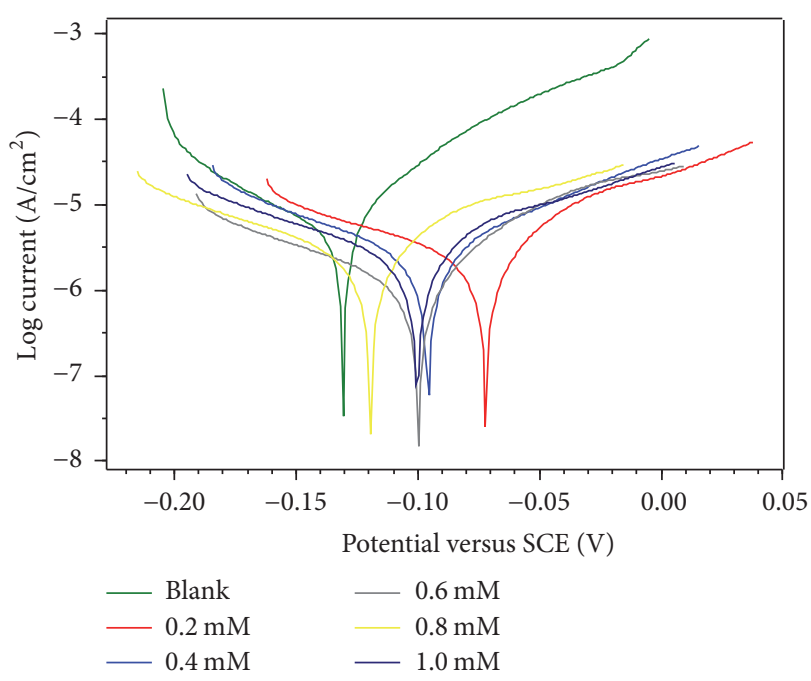

(b)

FIGURE 6: Tafel plots for $\mathrm{Cu}$ in the absence and presence of (a) 3APTSC and (b) $3 \mathrm{APPH}$ in $0.1 \mathrm{M} \mathrm{HNO}_{3}$.

specimen is very low, suggesting that hydrated oxide layer of copper is formed on the surface mainly by the reduction of oxygen at corrosion potential. From the table it is also evident that, with increasing concentrations of each compound, the corrosion current density $I_{\text {corr }}$ decreased considerably as compared to the blank and the corrosion inhibition efficiency was increased as the inhibitor concentration increased.

The electrochemical kinetic parameters of corrosion such as corrosion current density $I_{\text {corr }}$, corrosion potential $E_{\text {corr }}$, anodic Tafel constants $b_{a}$, cathodic Tafel constants $b_{c}$, and inhibition efficiency $\eta_{\text {pol }} \%$ were calculated from polarization curves and presented in Table 3.

On close examination of the Tafel plots of 3APTSC (Figure 6(a)) and electrokinetic parameters it may be concluded that the corrosion potentials of copper at various concentrations of 3APTSC change to cathodic and anodic directions and the inhibitive activity of this hydrazone can be regarded as a mixed type; that is, 3APTSC affects both cathodic and anodic process of corrosion more or less uniformly. Also the cathodic and anodic slopes of the Tafel curve change in each scan, which can be taken as an additional supporting evidence for the above argument. On evaluating the Tafel plots of copper in the presence and absence of $3 \mathrm{APPH}$ (Figure 6(b)), one can see the shifting of the corrosion potential towards the anodic direction which suggests that the 3APPH molecule inhibits the anodic process of corrosion appreciably. Since the anodic and cathodic slopes of the Tafel lines change from the blank, this molecule can also be regarded as the mixed type inhibitor, but predominantly anodic. The corrosion inhibition efficiencies of $3 \mathrm{APPH}$ on the copper metal surface were higher at all concentrations than the 3APTSC. These results are in good agreement with the results obtained by impedance analysis.

3.4. Surface Morphological Studies. To get more insight into the mechanism of corrosion inhibition, scanning electron 


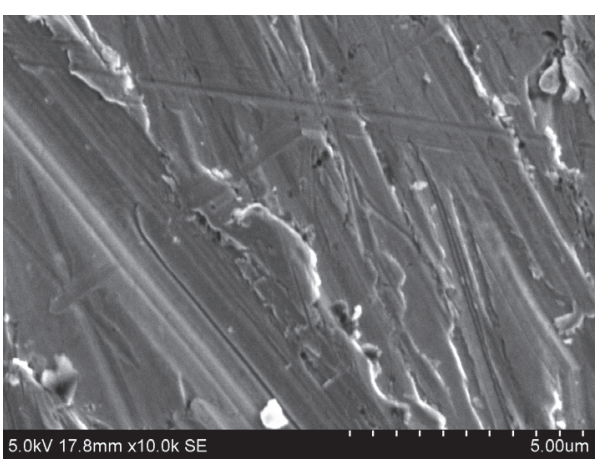

(a)

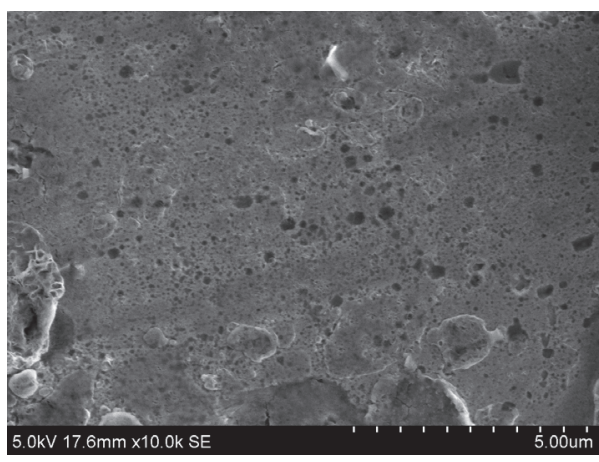

(c)

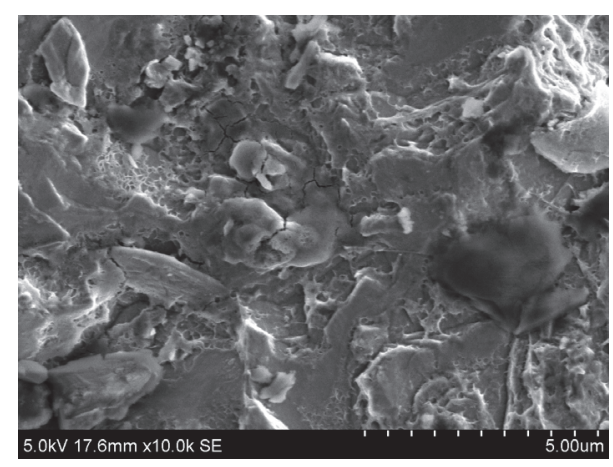

(b)

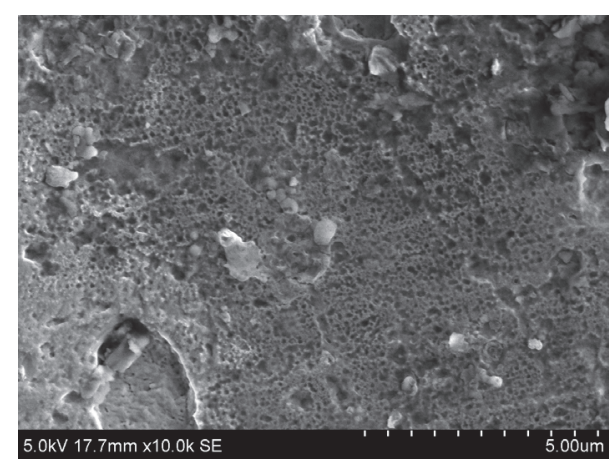

(d)

Figure 7: SEM images of (a) bare metal, (b) $\mathrm{Cu}$ in nitric acid (10 h), (c) $\mathrm{Cu}$ in the presence of $3 \mathrm{APPH}(1 \mathrm{mM})$ for $10 \mathrm{~h}$, and (d) Cu in the presence of 3APTSC $(1 \mathrm{mM})$ for $10 \mathrm{~h}$.

micrographs of the metal surfaces were taken in the absence and presence of the heterocyclic hydrazones. SEM analyses were conducted using Hitachi SU6600 model scanning electron microscope. On close examination of the figures it is obvious that a considerable difference can be noticed for the textures of bare metal surface, metal in nitric acid medium, and metal in the presence of heterocyclic hydrazones in nitric acid solution. The textures of Figures 7(a) and 7(b) are entirely different. The smoothness of the bare metal surface was completely lost in the presence of the corrodent nitric acid (Figure 7(b)). Surface images of copper specimens in the presence of the heterocyclic hydrazones (Figures 7(c) and $7(d)$ ) are entirely different from the morphology of metal in nitric acid. This is due the protective layer formation of the inhibitor molecules on the surface of the metal. On comparing Figures 7(c) and 7(d), it may be assumed that a visible thin protective layer of $3 \mathrm{APPH}$ is adhered on the copper surface which can be regarded as reason for the elevated inhibition efficiency of $3 \mathrm{APPH}$ compared to 3APTSC.

3.5. Quantum Chemical Calculations. The corrosion inhibition response of organic molecules can be correlated with the energy of frontier molecular orbitals. The donor-acceptor interaction (HSAB concept) between the filled molecular orbitals of the inhibitor molecules and the vacant orbitals of $\mathrm{Cu}$ atoms on the surface is very important in the prevention of metal dissolution. High value of $E_{\mathrm{HOMO}}$ and the lowest value of $E_{\mathrm{LUMO}}-E_{\mathrm{HOMO}}(\Delta E)$ are the important quantum chemical parameters which facilitate the strong binding of the molecules on the metal surface $[30,31]$. Optimization of geometry of molecules and quantum chemical calculations were performed by DFT method using GAMMES software. A combination of Beck's three-parameter exchange functional and Lee-Yang-Parr nonlocal correlation functional (B3LYP) was employed in DFT calculations [32]. Estimated quantum mechanical parameters like $E_{\mathrm{HOMO}}, E_{\mathrm{LUMO}}$, and $\Delta E$ for $3 \mathrm{APTSC}$ and $3 \mathrm{APPH}$ are provided in Table 4 . The HOMO and LUMO of the molecules are represented in Figure 8. Approximate HSAB parameters like electronegativity $(\chi)$ and chemical hardness $(\eta)$ of the molecules were evaluated by the following equations [33] and are reported in Table 4:

$$
\begin{aligned}
& \chi \approx-\frac{1}{2}\left(E_{\mathrm{HOMO}}+E_{\mathrm{LUMO}}\right) \\
& \eta \approx \frac{1}{2}\left(E_{\mathrm{HOMO}}-E_{\mathrm{LUMO}}\right) .
\end{aligned}
$$

The $E_{\mathrm{HOMO}}$ value of $3 \mathrm{APPH}$ was appreciably higher than that of 3APTSC. The energy separation between HOMO and LUMO was considerably lower for $3 \mathrm{APPH}$ than 3APTSC, which indicates that $3 \mathrm{APPH}$ is a finer inhibitor than 3APTSC. These data imply that the energy required to render electrons from $\mathrm{HOMO}$ of $3 \mathrm{APHH}$ to the vacant orbitals of $\mathrm{Cu}$ is low compared to that of 3APTSC. Quantum chemical parameters provide a room for the calculation of number of electrons transferred $(\Delta N)$ from donor to acceptor molecules. As an 
TABLE 4: Quantum chemical parameters of 3APPH and 3APTSC on copper.

\begin{tabular}{lccccrc}
\hline Molecule & $E_{\mathrm{HOMO}}(\mathrm{eV})$ & $E_{\mathrm{LUMO}}(\mathrm{eV})$ & $\Delta E(\mathrm{eV})$ & $\chi$ & \multicolumn{1}{c}{$\eta$} \\
\hline 3APPH & -2.9443 & 0.653078 & 3.597374 & 1.145608 & 1.798687 & 0.265533 \\
3APTSC & -3.22457 & 0.63403 & 3.858605 & 1.295272 & 1.929302 & 0.248446 \\
\hline
\end{tabular}
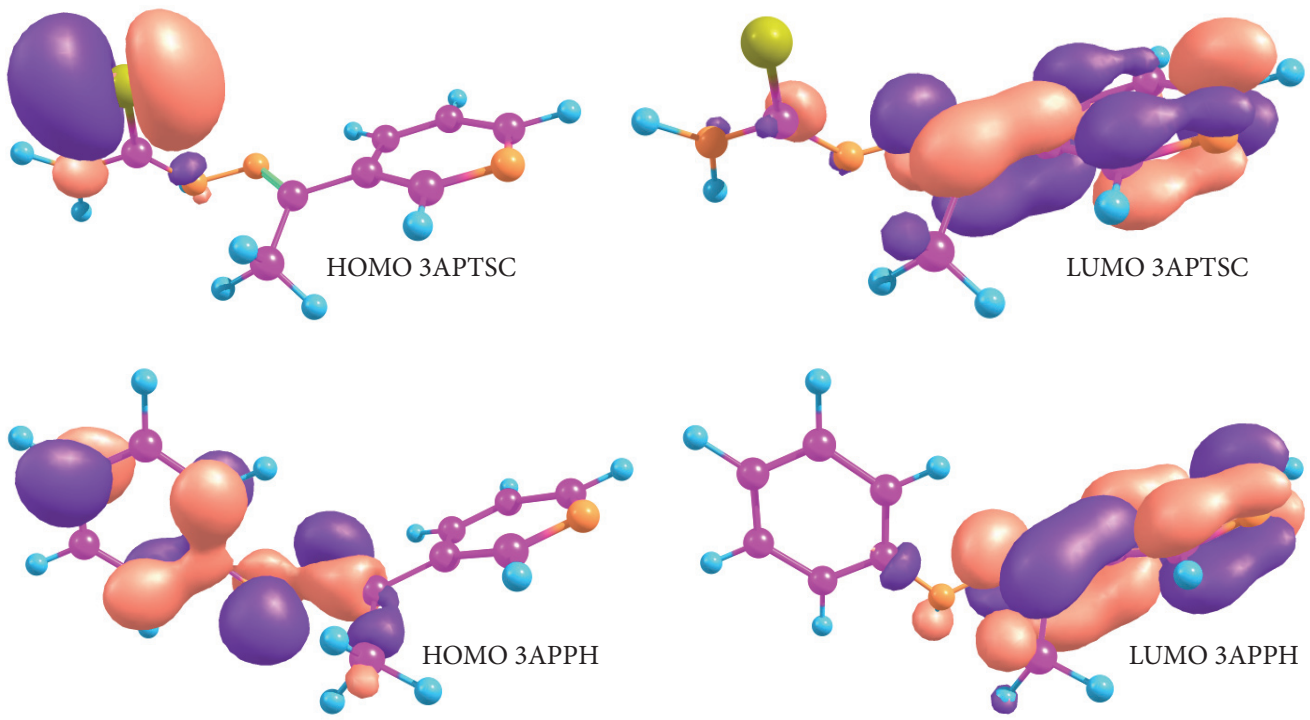

FIGURE 8: HOMO and LUMO of 3APTSC and 3APPH.

approximation, the chemical hardness of $\mathrm{Cu}$ metal is assumed as zero and the approximate electronegativity of bulk $\mathrm{Cu}$ is taken as $4.48 \mathrm{eV}$ [34]. Equation (11) gives the approximate quantity of electron transferred from the inhibitor molecule to the $\mathrm{Cu}$ atoms.

$$
\Delta N=\frac{\chi_{\mathrm{Cu}}-\chi_{\mathrm{inhib}}}{2\left(\eta_{\mathrm{Cu}}+\eta_{\mathrm{inhib}}\right)}
$$

The number of electrons transferred from the inhibitor to the acceptor atom is higher for $3 \mathrm{APPH}$, which suggests that this molecule makes a strong coordinate type interaction with the metal atoms.

\section{Conclusions}

(1) 3APPH exhibited very high corrosion inhibition efficiency on copper metal compared to 3APTSC in $0.1 \mathrm{M}$ $\mathrm{HNO}_{3}$ as per electrochemical studies.

(2) Presence of aromatic ring systems makes $3 \mathrm{APPH}$ a good corrosion inhibitor on copper surface.

(3) 3APTSC displayed $76 \%$ of maximum inhibition efficiency while $3 \mathrm{APPH}$ showed $92.5 \%$ as obtained by impedance studies at $1 \mathrm{mM}$ concentration.

(4) Both compounds obeyed Langmuir adsorption isotherm on copper metal in nitric acid

(5) Adsorption equilibrium constants established that the mechanism of inhibition involves both physisorption and chemisorption.
(6) Polarization studies revealed that both hydrazones act as a mixed type corrosion inhibitor. $E_{\text {corr }}$ values suggest that $3 \mathrm{APPH}$ interacts more at anodic sites.

(7) The reason for difference in the inhibitive capacity of molecules was explained by quantum chemical investigations.

\section{Competing Interests}

The authors declare that they have no competing interests.

\section{Acknowledgments}

The authors are grateful to TEQIP (phase II), Government Engineering College, Thrissur, Kerala, India, for the financial assistance in the form of seed money project.

\section{References}

[1] A. Zarrouk, T. Chelfi, A. Dafali et al., "Comparative study of new pyridazine derivatives towards corrosion of copper in nitric acid: part-1," International Journal of Electrochemical Science, vol. 5, no. 5, pp. 696-705, 2010.

[2] K. Barouni, L. Bazzi, R. Salghi et al., "Some amino acids as corrosion inhibitors for copper in nitric acid solution," Materials Letters, vol. 62, no. 19, pp. 3325-3327, 2008.

[3] A. A. El-Shafel, H. A. Mostafa, A. S. Fouda, and S. A. Abd El-Maksoud, "Inhibition of copper corrosion in $1 \mathrm{M}$ nitric acid with benzoyl benzaldehyde hydrazone derivatives," Materials and Corrosion, vol. 46, no. 8, pp. 468-472, 1995. 
[4] G. Karthik and M. Sundaravadivelu, "Investigations of the inhibition of copper corrosion in nitric acid solutions by levetiracetam drug," Egyptian Journal of Petroleum, vol. 5, pp. 696-705, 2015.

[5] E. M. Sherif and S.-M. Park, "Effects of 2-amino-5-ethylthio1,3,4-thiadiazole on copper corrosion as a corrosion inhibitor in aerated acidic pickling solutions," Electrochimica Acta, vol. 51, no. 28, pp. 6556-6562, 2006.

[6] E. Szőcs, Gy. Vastag, A. Shaban, and E. Kálmán, "Electrochemical behaviour of an inhibitor film formed on copper surface," Corrosion Science, vol. 47, no. 4, pp. 893-908, 2005.

[7] J. B. Matos, L. P. Pereira, S. M. L. Agostinho, O. E. Barcia, G. G. O. Cordeiro, and E. D'Elia, "Effect of cysteine on the anodic dissolution of copper in sulfuric acid medium," Journal of Electroanalytical Chemistry, vol. 570, no. 1, pp. 91-94, 2004.

[8] S. Li, L. Ni, C. Sun, and L. Wang, "Influence of organic matter on orthophosphate corrosion inhibition for copper pipe in soft water," Corrosion Science, vol. 46, no. 1, pp. 137-145, 2004.

[9] A. Dafali, B. Hammouti, R. Mokhlisse, and S. Kertit, "Substituted uracils as corrosion inhibitors for copper in $3 \% \mathrm{NaCl}$ solution," Corrosion Science, vol. 45, no. 8, pp. 1619-1630, 2003.

[10] N. Kuriakose, J. T. Kakkassery, V. P. Raphael, and S. K. Shanmughan, "Electrochemical Impedance spectroscopy and potentiodynamic polarization analysis on anticorrosive activity of thiophene-2-carbaldehyde derivative in acid medium," Indian Journal of Materials Science, vol. 2014, Article ID 124065, 6 pages, 2014.

[11] Zarrouk, B. Hammouti, H. Zarrok, M. Bouachrine, K. F. Khaled, and S. S. Al-Deyab, "Corrosion inhibition of copper in nitric acid solutions using a new triazole derivative," International Journal of Electrochemical Science, vol. 7, no. 1, pp. 89-105, 2012.

[12] I. El Ouali, B. Hammouti, A. Aouniti, M. Benabdellah, and S. Kertit, "Electrochemical behaviour of N,S-containing corrosion inhibitor for C38 Steel in molar HCL," Der Pharma Chemica, vol. 3, no. 5, pp. 294-300, 2011.

[13] A. Zarrouk, A. Dafali, B. Hammouti, H. Zarrok, S. Boukhris, and M. Zertoubi, "Synthesis, characterization and comparative study of functionalized quinoxaline derivatives towards corrosion of copper in nitric acid medium," International Journal of Electrochemical Science, vol. 5, no. 1, pp. 46-55, 2010.

[14] L. Li, Q. Qu, W. Bai et al., "Sodium diethyldithiocarbamate as a corrosion inhibitor of cold rolled steel in $0.5 \mathrm{M}$ hydrochloric acid solution," Corrosion Science, vol. 59, pp. 249-257, 2012.

[15] H.-L. Wang, H.-B. Fan, and J.-S. Zheng, "Corrosion inhibition of mild steel in hydrochloric acid solution by a mercaptotriazole compound," Materials Chemistry and Physics, vol. 77, no. 3, pp. 655-661, 2003.

[16] P. Lowmunkhong, D. Ungthararak, and P. Sutthivaiyakit, "Tryptamine as a corrosion inhibitor of mild steel in hydrochloric acid solution," Corrosion Science, vol. 52, no. 1, pp. 30-36, 2010.

[17] N. Soltani, M. Behpour, S. M. Ghoreishi, and H. Naeimi, "Corrosion inhibition of mild steel in hydrochloric acid solution by some double Schiff bases," Corrosion Science, vol. 52, no. 4, pp. 1351-1361, 2010.

[18] S. S. Abd El Rehim, M. A. M. Ibrahim, and K. F. Khalid, "The inhibition of 4-( $2^{\prime}$-amino- 5 ' methylphenylazo $)$ antipyrine on corrosion of mild steel in $\mathrm{HCl}$ solution," Materials Chemistry and Physics, vol. 70, no. 3, pp. 268-273, 2001.

[19] A. Raman and P. Labine, Reviews on Corrosion Inhibitor Science and Technology, NACE, Houston, Tex, USA, 1986.
[20] H. Ashassi-Sorkhabi, B. Shaabani, and D. Seifzadeh, "Effect of some pyrimidinic Shciff bases on the corrosion of mild steel in hydrochloric acid solution," Electrochimica Acta, vol. 50, no. 1617, pp. 3446-3452, 2005.

[21] S. S. Mahmoud, "Corrosion inhibition of iron by amphoteric surfactants in hydrochloric acid solutions," Journal of Materials Science, vol. 42, no. 3, pp. 989-997, 2007.

[22] M. El Achouri, S. Kertit, H. M. Gouttaya et al., "Corrosion inhibition of iron in $1 \mathrm{M} \mathrm{HCl}$ by some gemini surfactants in the series of alkanediyl- $\alpha, \omega$-bis-(dimethyl tetradecyl ammonium bromide)," Progress in Organic Coatings, vol. 43, no. 4, pp. 267273, 2001.

[23] S. Ramesh and S. Rajeswari, "Corrosion inhibition of mild steel in neutral aqueous solution by new triazole derivatives," Electrochimica Acta, vol. 49, no. 5, pp. 811-820, 2004.

[24] S. K. Shukla, M. A. Quraishi, and R. Prakash, "A self-doped conducting polymer 'polyanthranilic acid': an efficient corrosion inhibitor for mild steel in acidic solution," Corrosion Science, vol. 50, no. 10, pp. 2867-2872, 2008.

[25] E. Cano, J. L. Polo, A. L. A. Iglesia, and J. M. Bastidas, "A study on the adsorption of benzotriazole on copper in hydrochloric acid using the inflection point of the isotherm," Adsorption, vol. 10, no. 3, pp. 219-225, 2004.

[26] X. Li, S. Deng, H. Fu, and T. Li, "Adsorption and inhibition effect of 6-benzylaminopurine on cold rolled steel in 1.0 M HCl," Electrochimica Acta, vol. 54, no. 16, pp. 4089-4098, 2009.

[27] M. Pourbaix, Atlas of Elecrochemical Equilibria in Aqueous Solutions, NACE, Houston, Tex, USA, 1975.

[28] H. E. Johnson and J. Leja, "On the potential/ $p \mathrm{H}$ diagrams of the $\mathrm{Cu}-\mathrm{NH}_{3}-\mathrm{H}_{2} \mathrm{O}$ and $\mathrm{Zn}-\mathrm{NH}_{3}-\mathrm{H}_{2} \mathrm{O}$ systems technical notes," Journal of Electrochemical Society, vol. 112, no. 6, pp. 638-641, 1965.

[29] W. H. Smyrl, J. Bockris, B. E. Conway, E. Yeager, and R. E. White, Comprehensive Treatise of Electrochemistry, vol. 4, Plenum Press, New York, NY, USA, 1981.

[30] V. S. Sastri and J. R. Perumareddi, "Molecular orbital theoretical studies of some organic corrosion inhibitors," Corrosion, vol. 53, no. 8, pp. 617-622, 1997.

[31] W. H. Ailor, Handbook on Corrosion Testing and Evaluation, John Wiley \& Sons, New York, NY, USA, 1971.

[32] R. M. Issa, M. K. Awad, and F. M. Atlam, "Quantum chemical studies on the inhibition of corrosion of copper surface by substituted uracils," Applied Surface Science, vol. 255, no. 5, pp. 2433-2441, 2008.

[33] R. G. Pearson, "Absolute electronegativity and hardness: application to inorganic chemistry," Inorganic Chemistry, vol. 27, no. 4, pp. 734-740, 1988.

[34] S. Xia, M. Qiu, L. Yu, F. Liu, and H. Zhao, "Molecular dynamics and density functional theory study on relationship between structure of imidazoline derivatives and inhibition performance," Corrosion Science, vol. 50, no. 7, pp. 2021-2029, 2008. 

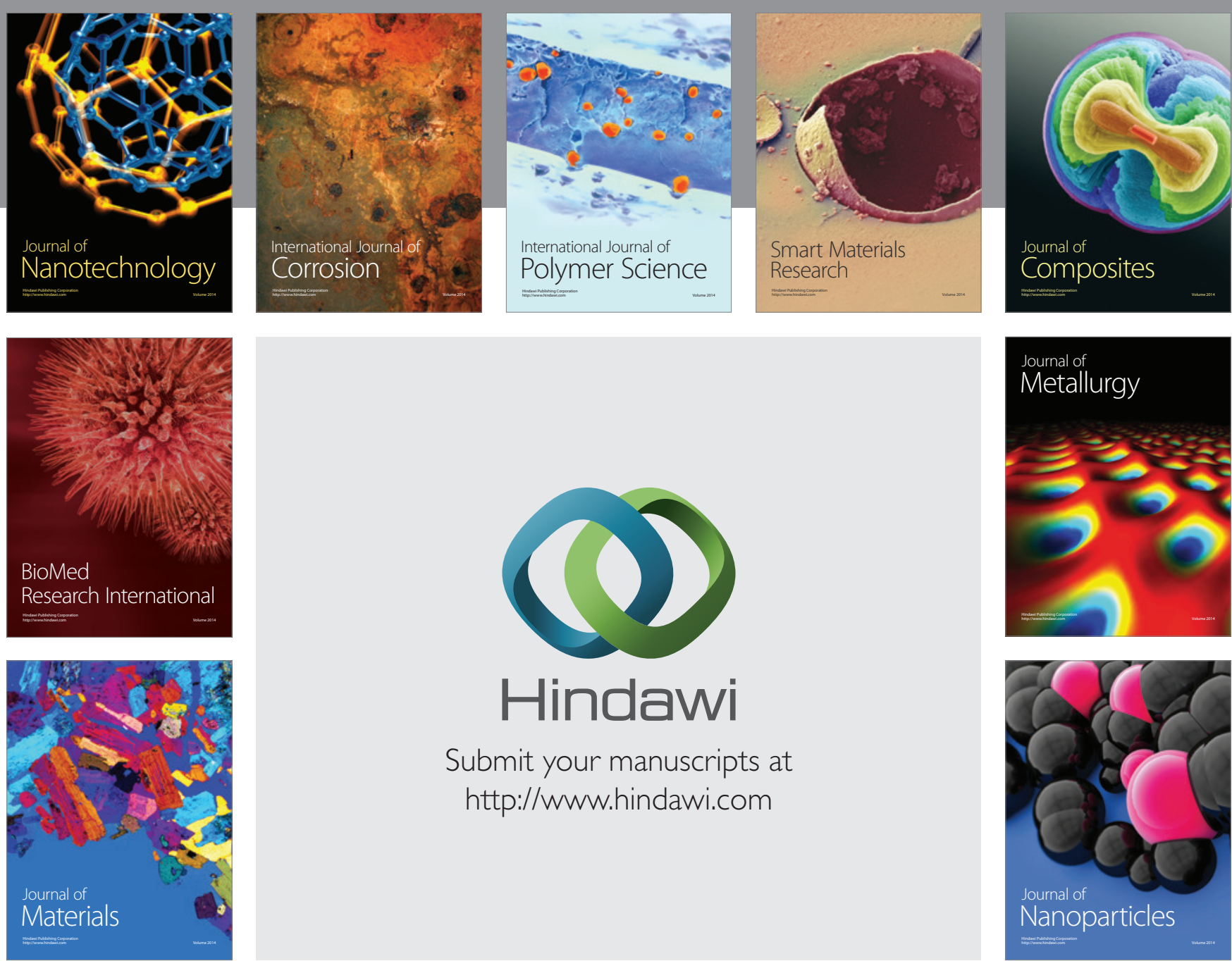

\section{Hindawi}

Submit your manuscripts at

http://www.hindawi.com

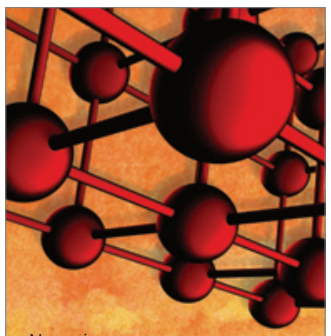

Materials Science and Engineering
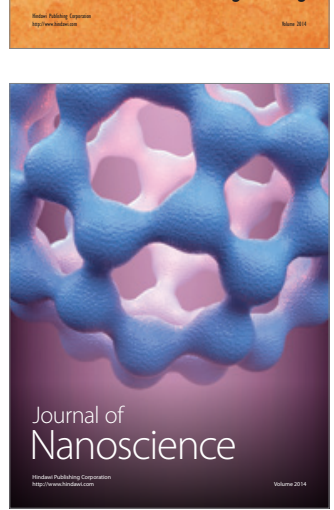
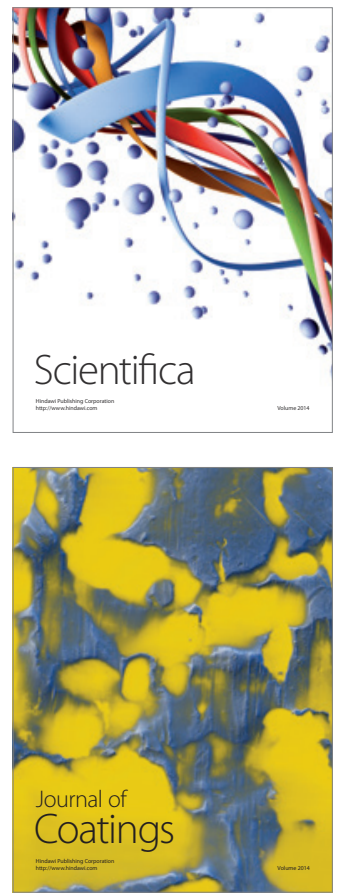
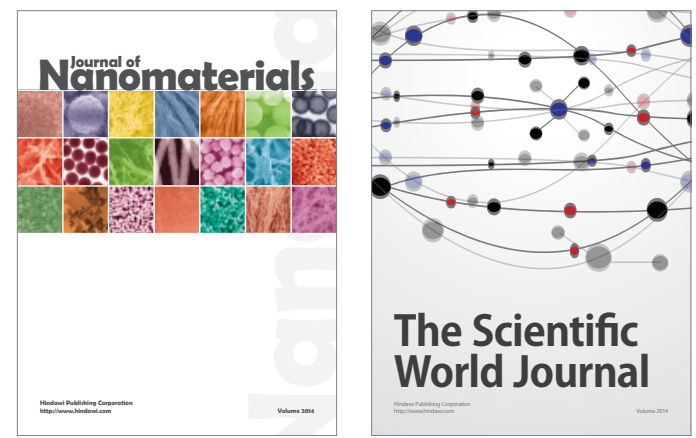

The Scientific World Journal
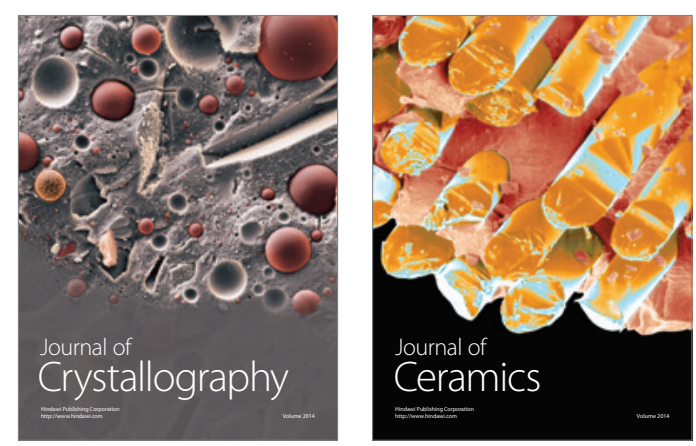
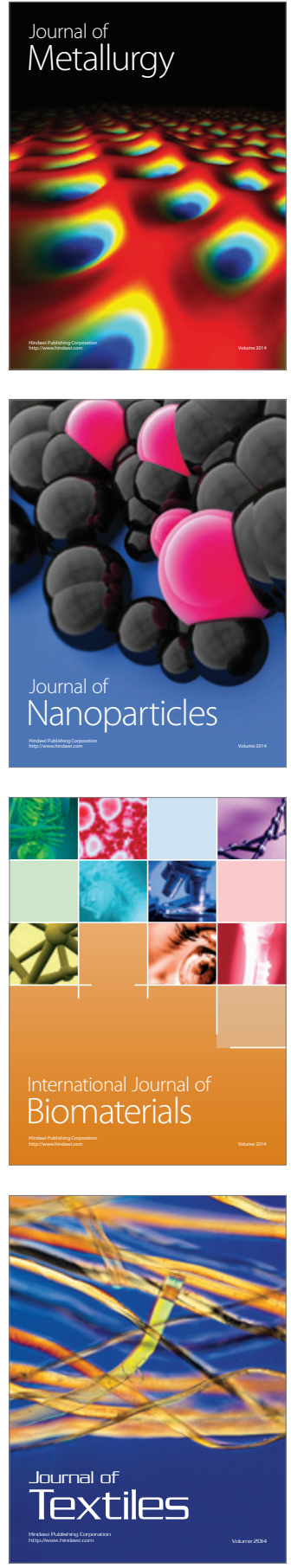